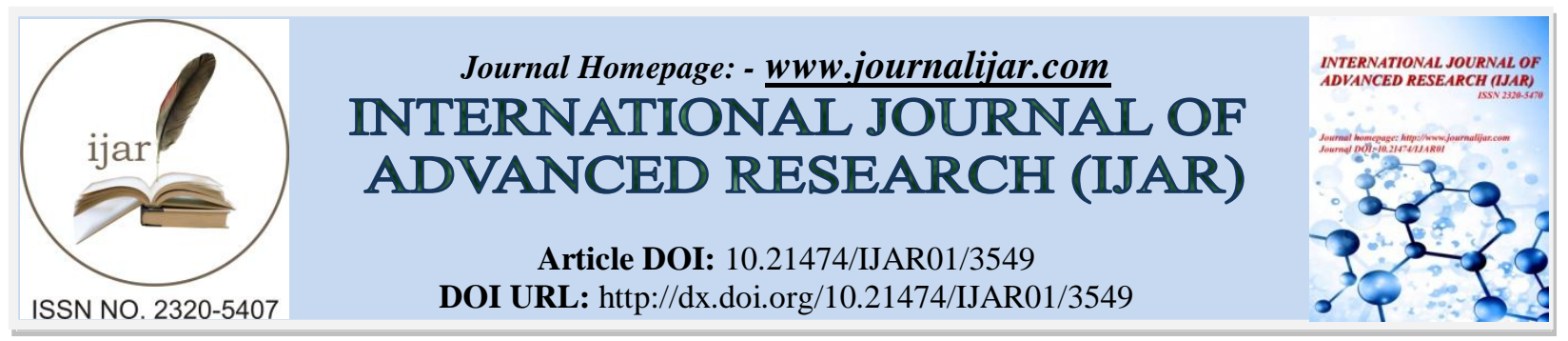

RESEARCH ARTICLE

\title{
EXPERIMENTAL STUDY ON SORPTION BEHAVIOR OF DESICCANTS
}

"Daya Lama, H. K. Gogoi and P. Sirinivas Raju.

Defence Research Laboratory, Tezpur -784001, Sonitpur, Assam, India.

\section{Manuscript Info}

Manuscript History

Received: 01 January 2017

Final Accepted: 08 February 2017

Published: March 2017

Key words:-

Desiccants, Adsorption, Humidity,

$\mathrm{CaCl}_{2}$, Temperature

\begin{abstract}
Moisture removal from air is a practice that is beneficial to many applications. One of the methods to separate water vapor from air is by using desiccants. Present work depicts water vapor sorption behavior of $\mathrm{CaCl}_{2}$, Silica gel, Molecular sieve, Bentonite powder and Aluminum oxide desiccants. In comparison to open air conditions, superior water vapor sorption was exhibited by all the desiccants in closed glass casings containing water, due to availability of higher humidity. After 141 hours of absorption time, $\mathrm{CaCl}_{2}$ absorbed $36.2 \%$ of its weight in open air conditions and $43.1 \%$ due to availability of higher humidity in closed glass casings having water. In comparatively lower humidity conditions prevailing in open air conditions, Molecular sieve exhibited superior adsorption capability than Silica gel while inside closed glass casings, Silica gel overpowered Molecular sieve during the later half of adsorption process. Regeneration experiments for desiccants showed that $100 \%$ regeneration of Silica gel and $\mathrm{CaCl}_{2}$ could be obtained when heated to around $117.5^{\circ} \mathrm{C}$ and $134^{\circ} \mathrm{C}$ respectively for 5 hours. $\mathrm{LiCl}$ and Molecular sieve indicated $70.6 \%$ and $59.7 \%$ regeneration respectively when heated to $140^{\circ} \mathrm{C}$.
\end{abstract}

Copy Right, IJAR, 2017,All rights reserved.

\section{Introduction:-}

Separation of moisture from air is a practice that is being used in many applications for achieving the desirable benefits. Some of the applications where practice of moisture removal from air is followed are in chemical industry to remove water produced by chemical reactions, air dehumidification air-conditioning system for comfortable and healthy environment [1,2], humidity control and air drying for industrial and agricultural sector like textile mills, post-harvest crop storage etc. [3], extracting water from air [4], control of humidity in food packaging [5], Moisture control in pharmaceutical [6] and electronics industry [7].

One of the methods to separate moisture from air is by using materials having affinity to attract water vapor and retain it in the form of water. Some of the commonly occurring materials that have the property to attract moisture from air are clay, sand, wood, sugar, caramel, honey, glycerol, table salts, polymers material such as cellulose, nylon etc. Commercially available materials having the property to attract water vapor from air are known as desiccants and the mechanism by which these materials attract and hold water vapor is adsorption or absorptions [8, 9]. Some of the desiccants are Calcium Chloride, Lithium Chloride, Lithium Bromide, Triethylene Glycol, Silica Gel, Aluminum silicates (Molecular sieve or Zeolites), Aluminum oxides, etc. These desiccants have been reported in many research works for sorption of water vapor molecules from air. As energy saving alternative Lithium chloride

Corresponding Author:- Daya Lama.

Address:- Defence Research Laboratory, Tezpur -784001, Sonitpur, Assam, India. 
has been used for air dehumidification and desiccant regeneration [10]. Molecular sieve has been used for dehydration of natural gas [11] and for understanding moisture adsorbing behavior [12]. It is also reported that hygroscopic Lithium bromide can be used for providing an attractive alternative to conventional cooling systems[13]. Triethylene glycol desiccant was used in cooling system for dehumidification and regeneration [14]. Water vapor adsorption by Silica gel has been studied for desalination [15]. Use of Calcium chloride is reported for absorption of water vapor from air [16].

The objective of the present work is to study through experimental trials water vapor sorption behavior of different desiccants and indentify their regeneration capability for reusable purpose.

\section{Theoretical background:-}

Desiccants attract moisture from air and thereby facilitate mass transport of water vapor molecule due to low vapor pressure created at the surface. Desiccants have low surface vapor pressure; this is due to the fact that it contains large surface area as a result of availability of pores. When these water molecules migrate at the surface due to low vapor pressure, adsorption occurs physically or chemically and in some cases by both the process. Desiccants like Silica gel, Molecular sieve, etc exhibits adsorption mechanism, whereby the water vapor molecules bind on a solid surface as a result of surface force attraction such as physical, electrostatic force or chemical adsorption. The molecular distances inside the pores of the adsorbent are much shorter than in the gaseous phase for similar pressure and temperature conditions and thus the adsorbate density in adsorbed phase becomes liquid-like due van der Waals attractive forces. When pore size is very small, another phenomenon called as capillary condensation occurs. Capillary effect is mainly due to intermolecular van der Waals forces, surface tension effect and wetting behavior of water on desiccant surface. Due to capillary effect there is lowering of vapor pressure over the surface of desiccant and thereby facilitates condensation process.

In case of metal chloride desiccants like $\mathrm{LiCl}, \mathrm{CaCl}_{2}$ and $\mathrm{LiBr}$ water vapor is attracted to these desiccants via absorption process. Due to this absorption process there is lowering of vapor pressure over the surface of these desiccants. During absorption, water vapor molecules completely dissolve and dissociate the ions of these desiccants. The driving force for absorption in this case is the negative enthalpy of reaction of water with these desiccants; in other words it is thermodynamically favorable to absorb water molecule. There is also a physical interaction between electropositive metal ions and lone pair of oxygen in water through ion-dipole force.

\section{Materials and Methods:-}

For studying water vapor sorption behavior, self indicating irregular granular Silica Gel of 3-4 mesh size [Merck Specialities Pvt. Ltd., India], Aluminium Oxide of particle size 0.05 to $0.15 \mathrm{~mm}$ [Merck Specialities Pvt. Ltd., India], 8 x 12 mesh Molecular sieve 4A (Sodium Alumino Silicate) [HiMedia Laboratories Pvt. Ltd., India], Bentonite powder (Aluminium Silicate) of size lesser than $25 \mu \mathrm{m}$ [HiMedia Laboratories Pvt. Ltd., India] and Calcium Chloride (fused) 95\% [Loba Chemie Pvt. Ltd., India] were considered. The desiccants chosen were all of general grade. The photograph of these desiccants is shown in figure 1. 


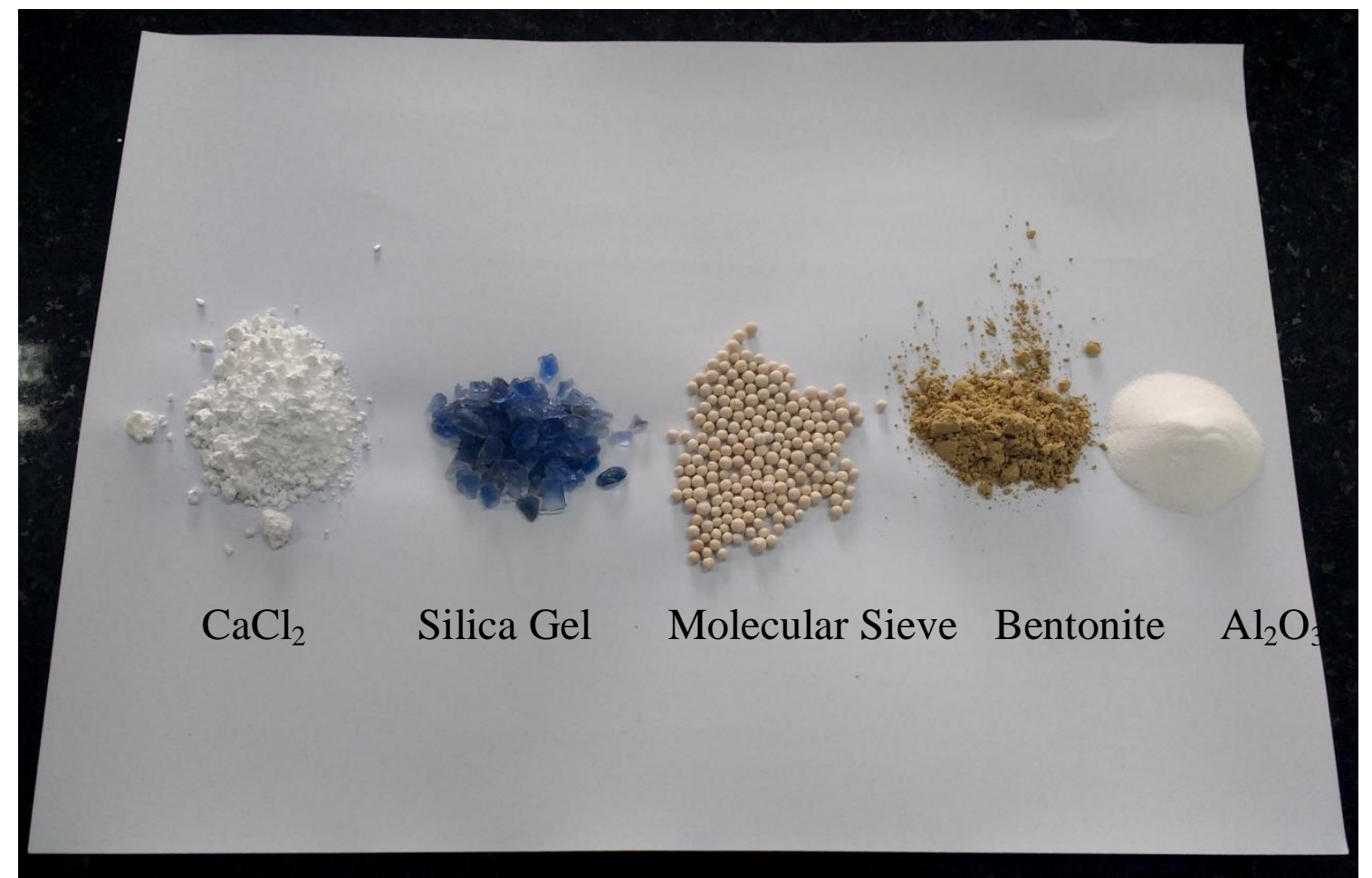

Figure 1:- Photograph showing Calcium Chloride, Silica Gel, Molecular Sieve, Bentonite powder and Aluminium oxide desiccants.

Two batches of experiments were carried out, one in open air condition and another inside closed glass casings containing disc with water, for higher humidity condition. In one batch of experiment $10 \mathrm{~g}$ each of the desiccant materials were kept in glass beakers for $141 \mathrm{hrs}$ in open air condition as shown in figure 2 . The air temperature and humidity were recorded to vary between $20^{\circ} \mathrm{C}$ to $26^{\circ} \mathrm{C}$ and $52 \%$ to $71 \%$ respectively during the duration of experiment. In another batch, same quantity of desiccants were kept inside glass beakers and the beakers were placed inside closed glass casings having disc containing water as shown in figure 3 . In this case due to water contained in the disc, humidity was observed to be $100 \%$.

Mass gained by the desiccants materials due to sorption of water vapor from air, in both the batches of experiments, were recorded at various intervals of time during the experiment and mass of water molecules held by desiccants were found out. In both the batches of experiments percentage of water collected, relative to the mass of desiccants, from atmospheric air were obtained for all the desiccants and graph showing variation of percentage sorption with time were plotted. 


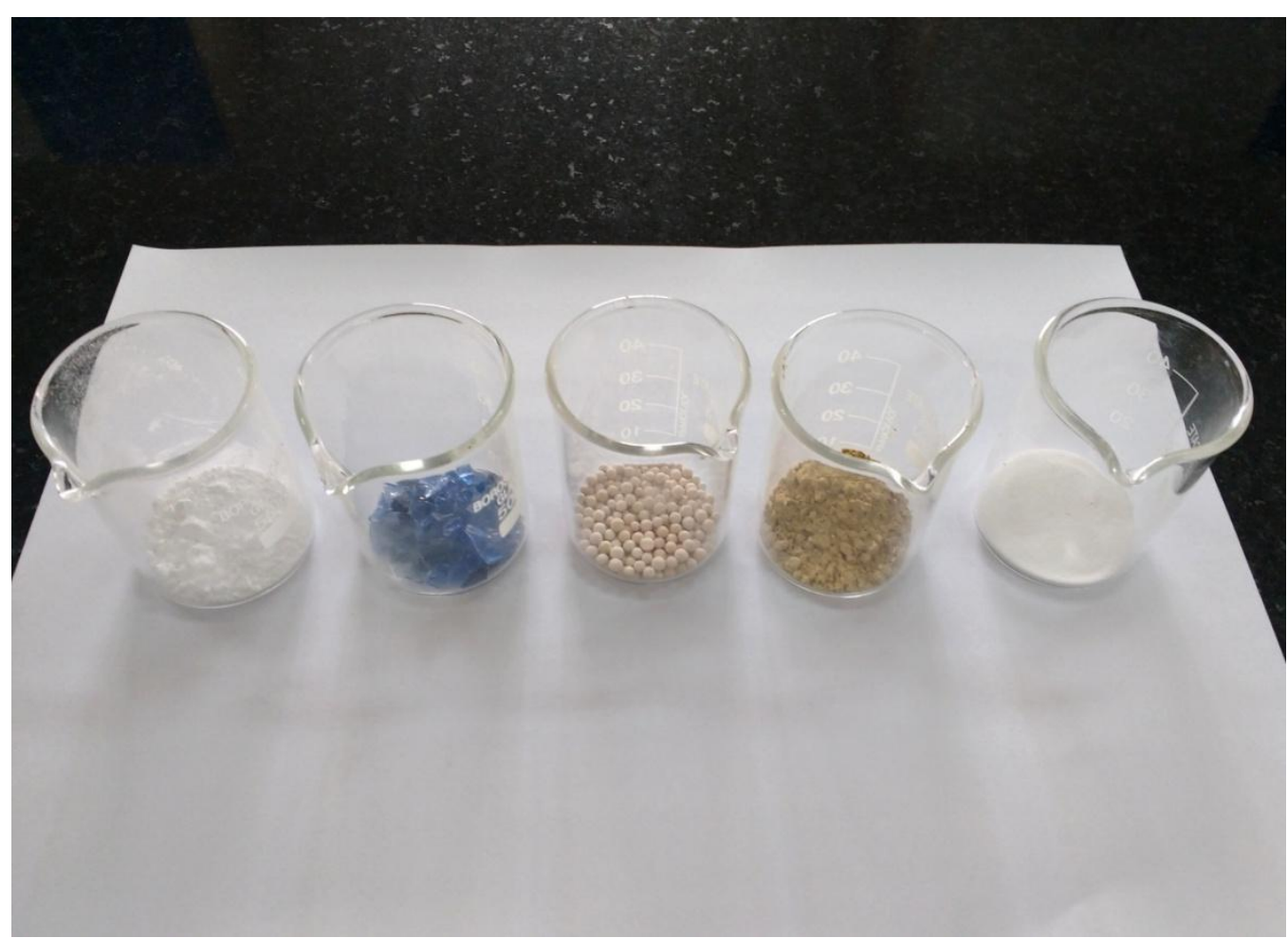

Figure 2:- Experimental setup for water vapor sorption in open air condition by desiccants.

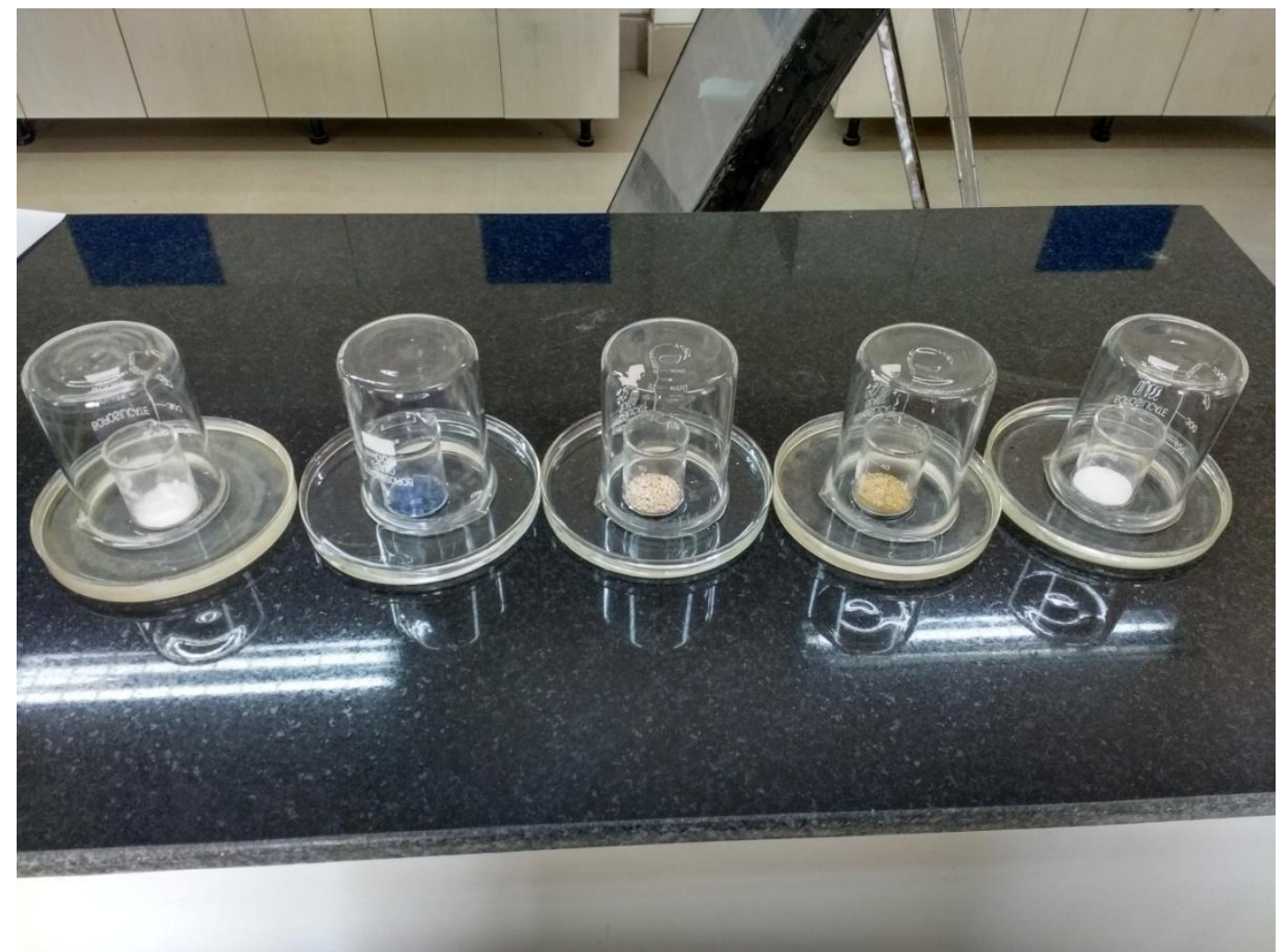

Figure 3:- Experimental setup for water vapor sorption in closed glass casings for higher humidity conditions.

For studying the regeneration temperatures $\mathrm{LiCl}, \mathrm{CaCl}_{2}$, Silica gel and Molecular sieve desiccants were taken into consideration. Four batches of $5 \mathrm{~g}$ each of $\mathrm{LiCl}, \mathrm{CaCl}_{2}$, Silica gel and Molecular sieve were placed like before inside 
a closed glass casings having disc containing water for 7 days and the relative humidity was observed to be $100 \%$ inside the glass casings. After 7 days of water vapor sorption by these desiccant materials, they were taken out from the glass casings and weighed in for quantifying the amount of water sorption. Immediately after sorption of water vapor, each batch of these desiccants was then heated for 5 hours in an oven at different temperatures. The temperatures chosen for heating the batches of desiccants were $110^{\circ} \mathrm{C}, 120^{\circ} \mathrm{C}, 130^{\circ} \mathrm{C}$ and $140^{\circ} \mathrm{C}$. After heating in the oven, desiccants were weighed again to obtain the amount of water lost due to heat. Percentage of water removed due to heating effect from the desiccants was calculated as the ratio of mass of water removed during heating and mass of water vapor held during the sorption period of seven days. Since percentage regeneration of desiccants is considered as percentage of moisture removed from the desiccants, graph showing variation of percentage regeneration of desiccants with heating temperatures was plotted.

\section{Results and Discussion:-}

\section{Sorption in open air conditions:-}

Water vapor absorbed/adsorbed at different intervals of time by 10 grams of each desiccant material in open air condition is shown in table 1.

Table 1:- Mass of water vapor held by desiccants at different intervals time in open air condition.

\begin{tabular}{|c|c|c|c|c|c|c|}
\hline \multirow[b]{2}{*}{ Desiccants } & \multicolumn{6}{|c|}{ Mass of water vapor absorbed/adsorbed } \\
\hline & $6 \mathrm{hrs}$ & $23 \mathrm{hrs}$ & $45 \mathrm{hrs}$ & $93 \mathrm{hrs}$ & $117 \mathrm{hrs}$ & $141 \mathrm{hrs}$ \\
\hline $\mathrm{CaCl}_{2}$ & 0.15 & 0.55 & 1.63 & 2.70 & 3.19 & 3.62 \\
\hline Silica Gel & 0.13 & 0.44 & 1.09 & 1.56 & 1.74 & 1.90 \\
\hline Molecular sieve & 0.17 & 0.64 & 1.80 & 2.07 & 2.09 & 2.09 \\
\hline Bentonite & 0.05 & 0.16 & 0.29 & 0.30 & 0.32 & 0.33 \\
\hline Aluminium oxide & 0.04 & 0.12 & 0.21 & 0.20 & 0.21 & 0.21 \\
\hline
\end{tabular}

It is found that during the experiment intake of water vapor by Bentonite powders and Aluminium oxide was significantly less and this is due to the fact that surface area of these desiccants are much lesser than of other desiccants. In comparison to Bentonite and Aluminium oxide, Silica gel was found to be superior desiccant with higher moisture adsorption of 1.90 grams in $141 \mathrm{hrs}$. The reason behind this is due to the internal structure of Silica gel, consisting of network of interconnected microscopic pores formed by connections of the polysilica gel particles via oxygen[17]. This structure causes large surface area in the range of $500 \mathrm{~m}_{2} / \mathrm{g}$ [18], producing a much reduced partial pressure of $0.13 \mathrm{~Pa}$ in an unsaturated state [19] and hence it has great affinity to adsorb water vapor. The adsorption process occurring in Silica gel is first by bonding of water molecule onto the hydroxyl groups of silica gel followed by further physical adsorption in additional layers by van der Waals forces, which are the decisive driving force for decreasing the vapor pressure [20]. At the end of experiment after 141 hrs of sorption process, $\mathrm{CaCl}_{2}$ was found to absorb highest amount of moisture 3.62 grams, 1.9 times more than by Silica gel, followed by Molecular sieve with 1.90 grams. The reason behind $\mathrm{CaCl}_{2}$ absorbing higher amount of moisture from air is due to thermodynamically favorable reaction of water molecule with $\mathrm{CaCl}_{2}$, having enthalpy of formation for hexahydrate as $-2218 \mathrm{~kJ} / \mathrm{mol}$. The bonding of water molecule with $\mathrm{CaCl}_{2}$ is due to electrostatic interactions of $\mathrm{Ca}^{2+}$ ions with lone pair of oxygen. And once the absorption initiates, vapor pressure at the surface of the $\mathrm{CaCl}_{2}$ lowers significantly facilitating higher absorption of water vapor.

Variation of percentage of water vapor intake with time by desiccants from air in open air condition at relative humidity between $52 \%$ and $71 \%$ is shown figure 4 . After 141 hours $\mathrm{CaCl}_{2}$ absorbs water vapor $36.2 \%$ of its weight, Molecular sieve and Silica gel adsorbs $20.9 \%$ and $19.0 \%$ of its weight. Whereas, Bentonite and Aluminum oxide 


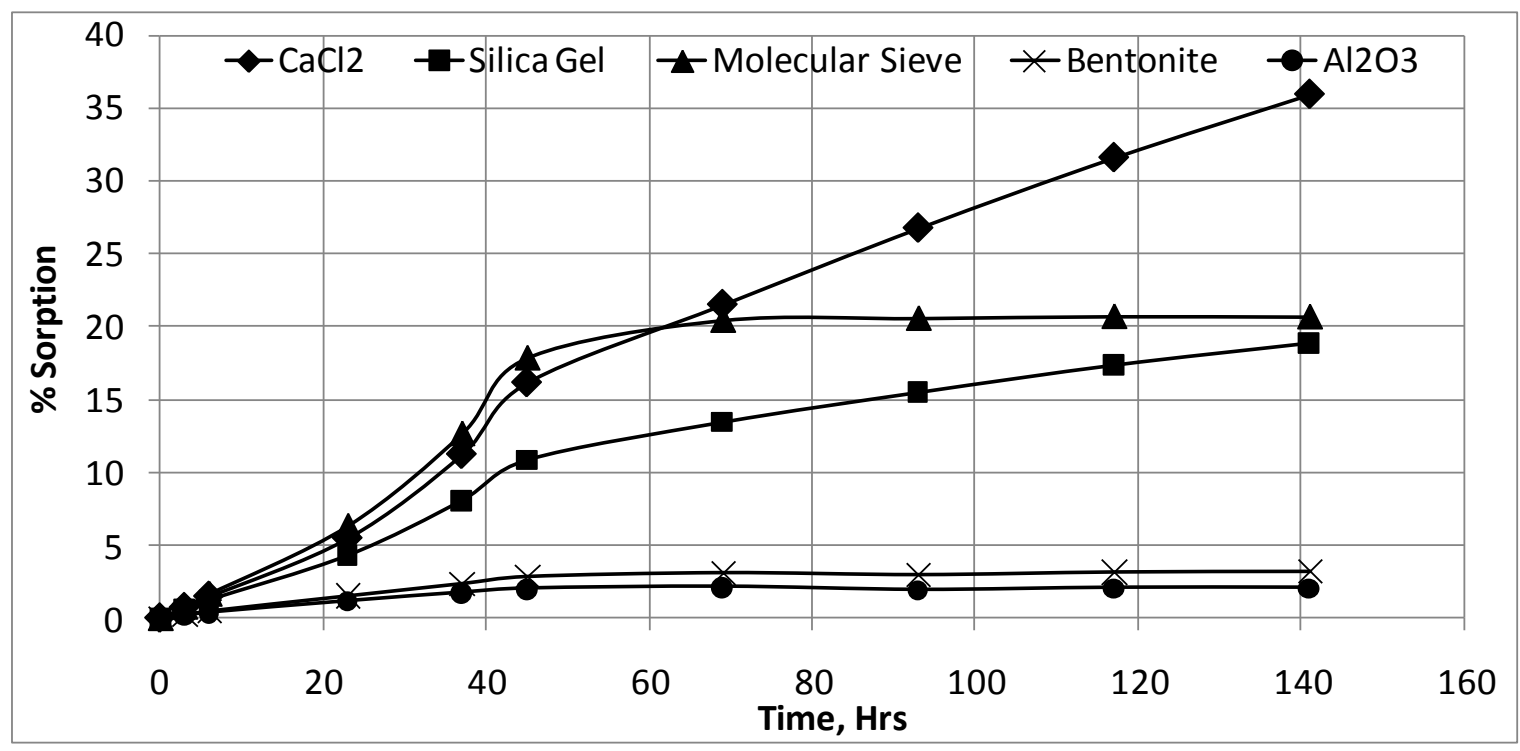

Figure 4:- Graph showing percentage sorption of water vapor by different desiccants in open air condition.

exhibits poor efficiency with water vapor adsorption of 3.3\% and $2.1 \%$ respectively. It is observed that Molecular sieve in open air conditions that is in lower humidity, exhibited superior adsorption behavior than Silica gel with higher amount of water vapor adsorption at any stage during the experiment. Even when compared to other desiccants, Molecular sieve showed relatively better adsorption capability from initial to 60 minutes of adsorption time. The reason for molecular sieve showing superior behavior to other desiccants at lower humidity is due to the fact that molecular sieve has uniform network of pores with uniform pore size [21, 22].

\section{Sorption in closed glass casings having higher humidity:-}

In case of higher humidity conditions that is experiment conducted in closed glass casings, water vapor intake with respect to time by 10 grams each of desiccant materials is shown in table 2 . In comparison to low humidity conditions in open air conditions, sorption of water vapor from air by all the desiccants were higher due to availability of higher humidity in closing glass casings having water disc. Like in open air condition here too $\mathrm{CaCl}_{2}$ showed superior absorption capacity with 4.31 grams of water at $141 \mathrm{hrs}$. Further effect of higher humidity on adsorbing behavior of Molecular sieve and Silica gel was also observed whereby after 141 hrs of adsorption time, unlike in open air condition Silica gel with 2.72 grams of water exhibited superior capability than molecular sieve.

Table 2. Mass of water vapor absorbed/adsorbed by desiccants at different intervals time in closed glass casings with higher humidity.

\begin{tabular}{|c|c|c|c|c|c|c|}
\hline \multirow[b]{2}{*}{ Desiccants } & \multicolumn{6}{|c|}{ Mass of water vapor absorbed/adsorbed } \\
\hline & $6 \mathrm{hrs}$ & $23 \mathrm{hrs}$ & $45 \mathrm{hrs}$ & $93 \mathrm{hrs}$ & $117 \mathrm{hrs}$ & $141 \mathrm{hrs}$ \\
\hline $\mathrm{CaCl}_{2}$ & 0.17 & 0.61 & 1.87 & 3.19 & 3.78 & 4.31 \\
\hline Silica Gel & 0.15 & 0.52 & 1.39 & 2.14 & 2.45 & 2.72 \\
\hline Molecular sieve & 0.17 & 0.66 & 1.92 & 2.16 & 2.18 & 2.19 \\
\hline Bentonite & 0.09 & 0.29 & 0.67 & 0.92 & 1.11 & 1.09 \\
\hline Aluminium oxide & 0.08 & 0.25 & 0.60 & 0.89 & 1.01 & 1.12 \\
\hline
\end{tabular}

Variation of percentage intake of water vapor with time by desiccants in higher humidity conditions is shown in figure 5. It is observed that due to higher humidity percentage sorption of water by desiccants is improved with Calcium Chloride absorbing as high as $43.1 \%$ after $141 \mathrm{hrs}$. 


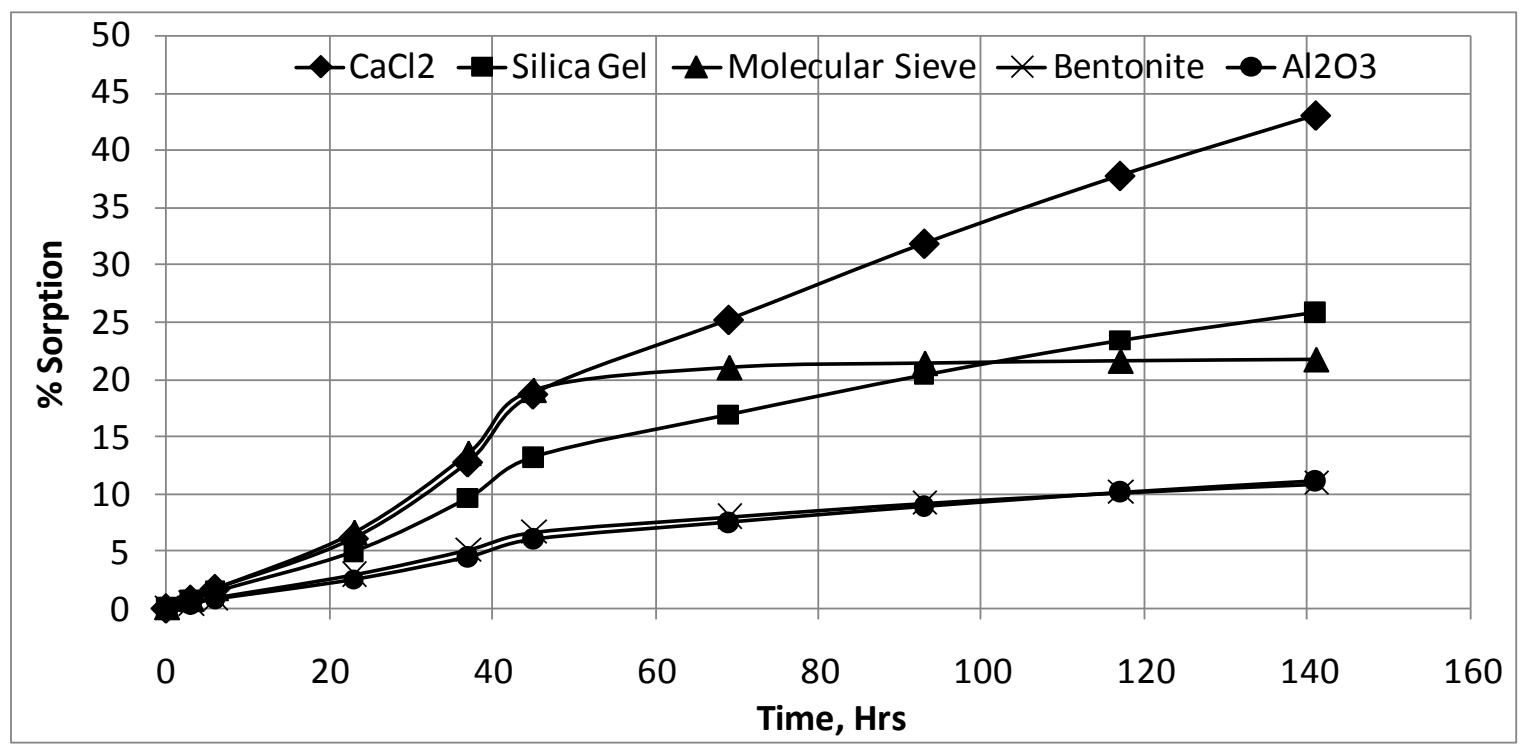

Figure 5:- Graph showing percentage sorption of water vapor by desiccants in closed glass casings having higher humidity condition.

Also compared to other desiccants, relatively higher improvement in adsorption of water vapor was seen in case of Aluminium oxide, $11.2 \%$ and Bentonite powder, 10.9\%; the margin of improvement in adsorption for Aluminium oxide and Bentonite was $9.1 \%$ and $7.6 \%$ respectively. As in lower humidity conditions, water vapor sorption rate was highest for Molecular sieve in initial part of adsorption process but in later half unlikely Calcium chloride showed exponential increase in moisture intake.

\section{Regeneration of desiccants:-}

Experimentation for studying regeneration temperature showed water sorption by 5 grams each of $\mathrm{LiCl}, \mathrm{CaCl}$, Molecular sieve and Silica Gel. Quantity of water vapor held by desiccants in seven days is shown in table 3 and water vapor removed later on after heating these desiccants at different temperature is shown in table 4.

Table 3:- Mass of water vapor held by desiccants in seven days.

\begin{tabular}{|l|l|l|l|l|}
\hline Desiccants & $\begin{array}{l}\text { Batch no.1 } \\
(\mathrm{g})\end{array}$ & $\begin{array}{l}\text { Batch no.2 } \\
(\mathrm{g})\end{array}$ & $\begin{array}{l}\text { Batch no. 3 } \\
(\mathrm{g})\end{array}$ & $\begin{array}{l}\text { Batch no. 4 } \\
(\mathrm{g})\end{array}$ \\
\hline $\mathrm{LiCl}$ & 5.48 & 6.93 & 7.08 & 6.52 \\
\hline $\mathrm{CaCl}_{2}$ & 4.84 & 6.03 & 6.18 & 2.97 \\
\hline Molecular sieve & 1.13 & 1.32 & 1.17 & 1.24 \\
\hline Silica Gel & 2.02 & 2.05 & 2.14 & 2.24 \\
\hline
\end{tabular}

Table 4:- Mass of water vapor removed from desiccants during heating in grams and percentage.

\begin{tabular}{|c|c|c|c|c|c|c|c|c|}
\hline \multirow[b]{2}{*}{ Desiccants } & \multicolumn{2}{|c|}{$\begin{array}{l}\text { Batch no.1 } \\
110^{\circ} \mathrm{C}\end{array}$} & \multicolumn{2}{|c|}{$\begin{array}{l}\text { Batch no.2 } \\
120^{\circ} \mathrm{C}\end{array}$} & \multicolumn{2}{|c|}{$\begin{array}{l}\text { Batch no. } 3 \\
130^{\circ} \mathrm{C}\end{array}$} & \multicolumn{2}{|c|}{$\begin{array}{l}\text { Batch no. } 4 \\
140^{\circ} \mathrm{C}\end{array}$} \\
\hline & $(\mathrm{g})$ & $(\%)$ & (g) & $(\%)$ & $(g)$ & $(\%)$ & (g) & $(\%)$ \\
\hline $\mathrm{LiCl}$ & 1.85 & $33.8 \%$ & 3.70 & $53.4 \%$ & 4.37 & $61.7 \%$ & 4.60 & $70.6 \%$ \\
\hline $\mathrm{CaCl}_{2}$ & 2.78 & $57.4 \%$ & 4.73 & $78.4 \%$ & 5.19 & $84.0 \%$ & 3.74 & $125.9 \%$ \\
\hline Molecular sieve & 0.45 & $39.9 \%$ & 0.69 & $52.3 \%$ & 0.64 & $54.7 \%$ & 0.74 & $59.7 \%$ \\
\hline Silica Gel & 2.20 & $108.9 \%$ & 2.34 & $114.1 \%$ & 2.38 & $111.2 \%$ & 3.29 & $146.8 \%$ \\
\hline
\end{tabular}

It is observed in case of $\mathrm{LiCl}$ and Molecular sieve, water vapor removal gradually increases with heating temperatures; water removal at $110^{\circ} \mathrm{C}$ is $33.8 \%$ for $\mathrm{LiCl}$ and $39.9 \%$ for Molecular sieve and whereas at higher temperature of $140^{\circ} \mathrm{C}$ mass of water vapor removed is increased to $70.6 \%$ and $59.7 \%$ respectively. Calcium chloride indicates $125.9 \%$ of water vapor removal at $140^{\circ} \mathrm{C}$ which suggest that heating temperature has exceeded the regeneration temperature and regeneration temperature is apparently $140^{\circ} \mathrm{C}$. While in case of Silica gel $108.9 \%$ 
water removal is observed even at $110^{\circ} \mathrm{C}$, which indicates that the regeneration temperature of silica gel is below $110^{\circ} \mathrm{C}$. Variation of percentage regeneration of desiccants with heating temperatures is shown in figure 5 .

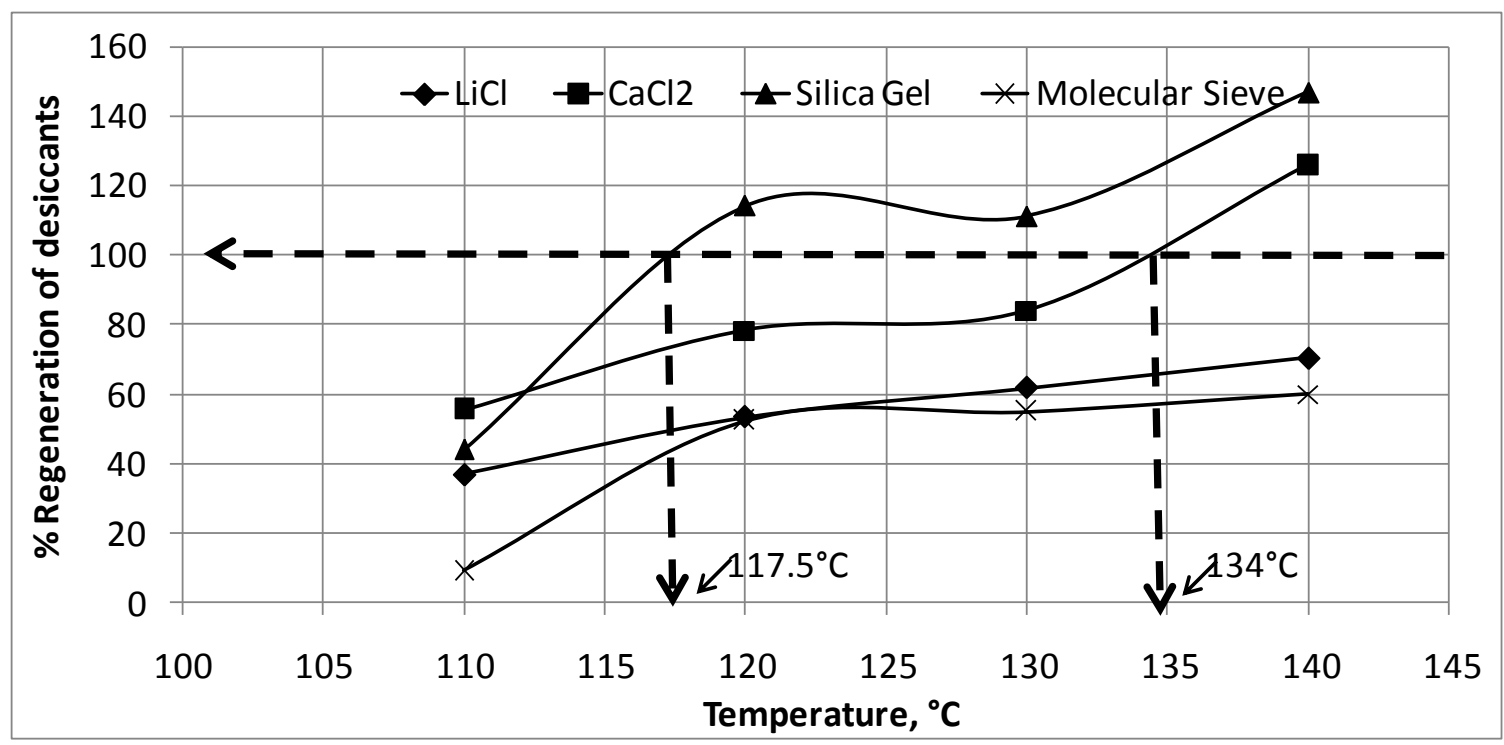

Figure 5:- Plot showing percentage regeneration of desiccants at different heating temperatures.

From the plot, it is observed that $100 \%$ regeneration of Silica gel and Calcium Chloride occurs when heated to around $117.5^{\circ} \mathrm{C}$ and $134^{\circ} \mathrm{C}$ respectively. These temperatures corresponding to $100 \%$ regeneration are regarded as the regeneration temperature of the Silica gel and $\mathrm{CaCl}_{2}$ when heating duration is 5 hours. In case of $\mathrm{LiCl}$ and Molecular sieve, even at highest experimental heating temperature of $140^{\circ} \mathrm{C}$ it did not give away all the moisture and showed incomplete regeneration.

\section{Conclusion:-}

Moisture removal from air by desiccant route is a viable method. Compared to Aluminium oxide and Bentonite powders, $\mathrm{CaCl}_{2}$, Molecular sieve and Silica gel are relatively more efficient for sorption of water vapor from air. Higher humidity condition generates higher sorption of water vapor from air by desiccants. Molecular sieve even at relatively lower humidity exhibits good adsorption capacity of water vapor molecules. The regeneration temperatures of Silica gel and $\mathrm{CaCl}_{2}$ is in present experimental study is observed to be $117.5^{\circ} \mathrm{C}$ and $134.0^{\circ} \mathrm{C}$ respectively, whereas $\mathrm{LiCl}$ and Molecular sieve desiccant showed $70.6 \%$ and 59.7\% regeneration respectively, when heated at 5 hours at $140^{\circ} \mathrm{C}$.

\section{Acknowledgement:-}

The authors gratefully thank for assistance and support provided by technical experts in chemistry department, DRL, Tezpur, Assam. The authors also acknowledge and thank all the authors who have been referred in this research paper.

\section{References:-}

1. Badrakia, H. C. (2015): Performance review of aqueous calcium chloride liquid desiccant based air dehumidifier for HVAC applications. A review. International Journal of Advanced Research in Engineering, Science

Technology., 2(12):38-49.

2. Singh, S. and Singh, K. (2015): An Experimental study on the performance of liquid desiccant dehumidification system. Mechanica Confab., 4(5):1-12.

3. Sahlot, M. and Riffat, S. B. (2016): Desiccant cooling systems: a review. International Journal of Low-Carbon Technologies., 11:489-505.

4. Gad, H. E., Hamed, A. M., El-Shaekawym, I. I. (2001): Application of a solar desiccant/collector system for water recovery from atmospheric air. Renewable Energy., 22:541-556. 
5. Mahajan, P. V., Rodrigues, F. A. S., Motel, A., Leonhard, A. (2008): Development of a moisture absorber for packaging of fresh mushrooms (Agaricus bisporous). Postharvest Biology and Technology., 48(3):408-414.

6. Naversnik, K. and Bohanec, S. (2008): Predicting drug hydrolysis based on moisture uptake in various packaging designs. European Journal of Pharmaceutical Sciences., 35(5):447-456.

7. Wong, E. H. and Rajoo, R. (2003): Moisture absorption and diffusion characterization of packaging materialsadvanced treatment. Microelectronics Reliability., 43(12):2087-2096.

8. Ovoshchnikov, D. S., Glaznev, I. S., Aristov, Y. I. (2011): Water sorption by the calcium chloride/silica gel composite: The accelerating effect of the salt solution present in the pores. Kinetics and Catalysis., 52(4):620628.

9. Solomon, I., Ribeiro, A. M., Santos, J. $\quad$ C., $\quad$ Loureiro, J. M., Rorrigues, A. E., Sandu, I., Mamaliga, I. (2013): Adsorption equilibrium of water vapor on activated carbon and alumina carbon and alumina impregnated with hygroscopic salt. Turkish Journal of Chemistry., 37:358-365.

10. Fumo, N. and Goswami, D. Y. (2002): Study of an aqueous Lithium Chloride desiccant system: air dehumidification and desiccant regeneration. Solar Energy., 72(4): 351-361.

11. Hassan, A. A., $\quad$ Farag., Mustafa, M. $\quad$ E., Hoda, Adel, W. N. (2011): Natural gas dehydration by desiccant materials. Alexandria Engineering Journal., 50:431439.

12. Tao, P., Liao, B., Tan, Y. (2012): A primary study on the water absorbing/releasing performance of molecular sieve desiccant. Procedia Engineering., 27:781-786.

13. Bouzenada, S., Kaabi, A.N., Fraikin, L., Leonard, A. (2014): Experimental study on dehumidification/regeneration of liquid desiccant: $\mathrm{LiBr}$ solution. Procedia Computer Science., 32:673-680.

14. Vias, A. K. and Thakur, R. (2014): Performance of the Cross Flow Regenerator Used in Liquid Desiccant Dehumidification. International Journal of Recent Development in Engineering and Technology., 3(3):100-107.

15. Cevallos, O. R. F. (2012): Adsorption Characteristics of Water and Silica Gel System for Desalination Cycle. Thesis in Partial Fulfillment of the Requirements For the Degree of Master of Science King Abdullah University of Science and Technology Thuwal, Kingdom of Saudi Arabia.

16. Ahmed, M. H., Ayman, A. A., El-Shafei, B. Z. (2011): Application of Solar Energy for Recovery of Water from Atmospheric Air in Climatic Zones of Saudi Arabia. Natural Resources., 2:8-17.

17. Chih-Hang, H. (1980): Vapor pressure lowering in porous media, dissertation, Standford University.

18. Jokisch, F. (1975): On the mass transfer in the hygroscopic field of capillary-porous materials with an example of the water-vapour transport in technical adsorbents. Dissertation., Technical High School, Darmstadt.

19. Willmes, A. (1992): Handbook of Chemical Substances. Verlag Harri, Frankfurt am Main.

20. Gerrit, H. (2001): Desiccant Cooling with Solar Energy. Dissertation for degree of Doctor of Philosophy., De Montfort University, Institute of Energy and Sustainable Development, Stuttgart.

21. Golubovic, M. N., Hettiarachchi, H. D. M., Worekr, W. M. (2006): Sorption properties for different types of molecular sieve and their influence on optimum dehumidification performance of desiccant wheels. Heat Mass Transfer., 49:2802-9.

22. Aristov, Y., Glazneva, I. S., Frenib, A., Restuccia, G. (2003): Kinetics of water sorption on SWS-1L (calcium chloride confined to mesoporous silica gel). Influence of grain size and temperature. Chem Eng Sci., 61:14531458 . 